\title{
ETKİNLİK ÖLÇÜMÜ: TEKSTİL SEKTÖRÜNDEN BİR İŞLETME ÖRNEĞİ
}

\author{
Nuri Özgür DOĞAN ${ }^{1}$ \\ Yusuf ERSOY2
}

Atıf/(): Doğan, Nuri Özgür; Ersoy, Yusuf (2017). Etkinlik Ölçümü: Tekstil Sektöründe Bir İşletme Örneği, Hitit Üniversitesi Sosyal Bilimler Enstitüsü Dergisi, Yıl 10, Sayı 1, Haziran 2017, ss. 35-44

Özet: Etkinlik, kaynakların kullanılması ile ilgili bir kavramdır. İşletmeler girdi adı verilen kaynakların, belirli bir süreçten geçirerek çıtı adı verilen yeni ürün ya da hizmete dönüştürürler. Bu dönüşüm sürecinde kaynaklarn ne denli etkin kullanıldiğının bilinmesi işletmelere maliyet avantajı olarak yansıyacaktır. Bu çalışmada Ege Bölgesi'nde faaliyet gösteren bir tekstil işletmesi ele alınmış ve bu üretici işletmenin etkinlik düzeyi VZA yöntemi kullanılarak belirlenmeye çalışılmıştır. Bu kapsamda söz konusu işletmenin geçmiş on altı yıla ilişkin etkinlik ölçümü yapılarak her bir yıldaki kaynaklar kullanma düzeyinin belirlenmesi amaçlanmıştır. Her bir yıl bir karar verme birimi olarak alınmış, girdiler ve çıtıllar da işletmenin üretim sürecini yansıtacak şekilde belirlenmiştir. Yapılan etkinlik ölçümü sonucunda araştırmaya konu olan işletmenin hangi yıllarda etkin olduğu ve hangi yıllarda etkin olmadiğı bulunmuştur. Çalışmadan elde edilen bulguların işletmenin yöneticilerine kaynakların rasyonel kullanımı noktasında yardımcı olabileceği düşünülmektedir. Ayrıca, çalışmanin kısıtlarından bahsedilmiş ve gelecekte bu konu ile ilgili yapılacak araştırmalar için bir takım öneriler de sunulmuştur.

Anahtar Kelimeler: Etkinlik Ölçümü, Veri Zarflama Analizi, Tekstil Sektörü.

Makale Geliş Tarihi: 11. 01. 2017/ Makale Kabul Tarihi: 30.05.2017

1 Doç. Dr., Nevşehir Hacı Bektaş Veli Üniversitesi, İktisadi ve İdari Bilimler Fakültesi, İşletme Bölümü, e-posta: nodogan@nevsehir.edu.tr

2 Uzman, Uşak Üniversitesi, Bilimsel Analiz ve Teknolojik Araştırma ve Uygulama Merkezi, e-posta: yusuf.ersoy@usak.edu.tr 


\section{Efficiency Measurement: A Case Study of A Firm in The Textile Sector}

Citation/(): Doğan, Nuri Özgür; Ersoy, Yusuf (2017). Efficiency Measurement: A Case Study of A Firm in The Textile Sector, Hitit University Journal of Social Sciences Institute, Year 10, Issue 1, June 2017, pp. 35-44

Abstract: Efficiency is a concept related to the usage of the resources. Firms transform their resources (inputs) into new products or services (outputs) by using a process. In this transformation process the firms would take cost advantage by knowing how efficient the reources are used. In this study a textile firm operating in the Aegean Region was taken and the efficiency level of this manufacturing firm was tried to be determined by using DEA methodology. In this context, efficiency measurement of the firms in the past sixteen years was made with the aim of specifying the level of resource usage in each year. Each year was taken as a decision making unit and the inputs and outputs were determined suitably with the production process of the firm. As a result of the efficiency measurement it was found that in which years the firm was efficient and in which years it was inefficient. It was thought that the findings of this study could be helpful for the management of the firm concerning the use of the resources. Furthermore, limitations of the study and future research directions were discussed.

Keywords: Efficiency Measurement, Data Envelopment Analysis, Textile Sector.

\section{GIRIŞ}

Tekstil ve hazır giyim sektörü, gelişmekte olan ülkelerin kalkınmalarında önemli rol almıştır. Tekstil sektörünün sağladığı katma değer ve istihdam üzerindeki pozitif etkisi, ülkelerin ekonomik anlamda gelişmelerinde ve refah seviyelerinin artışında etkili olmuştur. Gelişmiş ülkelerde iş gücü maliyetinin yüksekliğinden dolayı emek yoğun bir sektör olan tekstil sektörü gelişmekte olan ülkelere doğru kaymıştır (Sarıçam ve Erdumlu, 2012: 519). Küresel ekonomide rekabet gücünün artırılması ve firmaların sürekliliğinin sağlanması için tekstil ve hazır giyim firmalarının modernize edilerek yüksek kaliteli ürünler üzerine odaklanma zorunluluğu ortaya çıkmıştır (Kapelko ve Lansink, 2014: 1500).

Hazır giyim sektörü genel olarak örme ve dokuma kumaşlardan çocuk, kadın ve erkekler için dış ve iç giysi üretimini içerisinde barındıran bir sektördür. Tekstil sektörü beş önemli alt gruptan oluşmaktadır. Bu gruplar; iplik, dokuma, örme, dokusuz yüzey ve tekstil terbiye alanlarıdır. Tekstil sektörü, elyaftan mamul ürün üretimine kadar çok uzun bir tedarik zinciri ağına sahiptir (Öngüt, 2007: 4; Alüftekin vd., 2009: 2). 
Dünya tekstil ihracatının 2013 yılında 2012 yılına göre \%3 oranında artığı ve 344,54 milyar dolar düzeyinde 2012 yılında ise 2011 yılına göre \% 4,5 oranında azalarak 334,37 milyar dolar düzeyinde gerçekleştiği bilinmektedir. 2013 yılı baz alınarak ülkelere göre ihracat değerlendirildiğinde ise Çin’in tek başına 108,96 milyar dolar ile toplam dünya tekstil ihracatının \% 31,6'sını yaptığı anlaşılmaktadır. Çin'i sırasıyla dünya tekstil ihracatının \% 23,4'ünü yapan Avrupa Birliği, \%7,1'ini yapan Hindistan, \%6,3'üni yapan Amerika Birleşik Devletleri, \%4,8'ini yapan Almanya, \%4,1'ini yapan İtalya, \% 4'ünü yapan Kore ve \%3,7'sini yapan Türkiye takip etmektedir. Veriler değerlendirildiğinde tekstil ve hazır giyim sektöründe ihracat ve üretim konusunda Çin'in dünya lideri konumunda olduğu görülmektedir (Bilim ve Sanayi Bakanlığ1, 2016).

Türk tekstil ve hazır giyim sektörü 2009 yılında yaşanan ekonomik krizden diğer birçok sektör gibi olumsuz bir şekilde etkilenmiştir. 2009 yıli ihracat rakamlarında 2008 yılı ihracat rakamlarına göre hazır giyimde $\% 16,5$, tekstil sektöründe ise \%15'5 oranında azalma görülmüştür. Türkiye istatistik Kurumu (TÜİK) verileri incelendiğinde Türkiye'nin 2010-2015 y1lları arasındaki toplam tekstil sektörü ihracatının 80 milyar 858 milyon dolar ve hazır giyim sektöründeki toplam ihracatının 73 milyar 210 milyon dolar olduğu anlaşılmaktadır. 2010-2015 yılları arasında en fazla ihracatın 2014 yılında olduğu ve tekstil sektöründe 15 milyar 413 milyon dolar, hazır giyim sektöründe ise 12 milyar 703 milyon dolar düzeyinde gerçekleştiği görülmektedir. Türkiye'nin 2010-2015 yılları arasındaki toplam ihracatı 854 milyar 508 milyon dolar, 2010-2015 yılları arasındaki tekstil ve hazır giyim sektörü toplam ihracatı ise 154 milyar 69 milyon dolar düzeyindedir. 20102015 yılları arasında tekstil ve hazır giyim sektörü ihracatının Türkiye'nin toplam ihracatındaki payının \%18'lik kısmını oluşturduğu görülmektedir (TÜİK, 2016).

Battaniye, yün, pamuk, polyester veya akrilik gibi hammaddelerden imal edilmiş yatağın üzerine konulan ve yorgan yerine kullanılan örtü olarak bilinmektedir (Bilgin, 2005: 1). Türk battaniye sektörü üretim yapısından dolayı emek yoğun bir sektördür ve bu sektörde faaliyet gösteren işletmelerin birçoğu aile şirketi konumundadır (Bilgin, 2005: 9). Son zamanlarda rekabetin giderek artması ve uzak doğu ülkelerindeki ucuz enerji ve iş gücü Türk battaniye sektörünü de tehdit etmektedir. Bu açıdan değerlendirildiğinde birçok sektörde olduğu gibi battaniye sektöründe de rakiplerle rekabet etmek ve sürekliliği sağlamak için etkinlik ve verimlilik kavramlarına her zamankinden daha fazla önem verilmesi gerekmektedir.

Bu çalışmada işletme performansının değerlendirilmesi ele alınmış ve bu amaçla etkinlik ölçümüne odaklanılmıştır. Literatürde etkililik, etkinlik ve verimlilik kavramları hususunda bir kargaşa yaşanmaktadır (Yükçü ve Atağan, 2009: 1). Etkinlik, bir ürün veya hizmet üretebilmek için gerekli 
kaynakların işletme amaçları doğrultusunda ne kadar etkin olarak kullanıldığını gösteren bir kavram olarak bilinmektedir. Etkinlik kavramı aynı zamanda standart performansın gerçekleşen performansa oranı olarak bilindiğinden işletmeler için oldukça önemlidir (Yükçü ve Atağan, 2009: 3; Doğan, 2015: 188 ). Bu çalışmanın amac1, Ege bölgesinde tekstil sektöründe faaliyet gösteren bir battaniye işletmesinde etkinliğin ölçülmesidir. Etkinlik ölçümü Veri Zarflama Analizi (VZA) yöntemi kullanılarak yapılmıştır.

Çalışmanın ikinci bölümünde VZA metodu kullanılarak gerçekleştirilmiş çalışmalara ilişkin literatür özeti verilmiştir. Üçüncü bölümde çalışmanın yöntemi hakkında bilgi verilmiş, dördüncü bölümde elde edilen analiz sonuçları ve bulgulara yer verilmiştir. Çalışma genel bir değerlendirilmenin yapıldığı sonuç bölümüyle tamamlanmıştır.

\section{LİTERATÜR ARAŞTIRMASI}

Literatürde VZA kullanılarak gerçekleştirilmiş çok sayıda çalışmaya rastlamak mümkündür. VZA analizi mal ve hizmet üretimi yapan işletmelerde etkinlik, verimlilik ya da performans ölçümünde kullanılan yöntemlerden birisidir. Bu bölümde tekstil sektöründe VZA yöntemi kullanılarak gerçekleştirilmiş çalışmalara ilişkin literatür özetine yer verilmiştir.

İMKB'de işlem gören 22 tekstil işletmesinin etkinliği (Çetin, 2006: 255), 2004 yılında "En Büyük 500 Özel Firma" sıralamasına giren 43 firmanın etkinliği (Bakırc1, 2007: 327), İMKB Tekstil Sektörü "Dokuma, Giyim Eşyası ve Deri" alt sektöründe bulunan 31 adet işletmenin etkinliği (Dinçer, 2008: 825), Hindistan tekstil sektöründe faaliyet gösteren 24 adet hazır giyim firmasinın 2003-2007 yılları arasındaki etkinliği (Joshi ve Singh, 2009: 19), 2007 yılında Türkiye'nin En Büyük 500 Şirketleri araştırması kapsamında tekstil sektöründe faaliyet gösteren 30 işletmenin etkinliği (Kayalı, 2009: 3), İMKB Tekstil Sektörü içerisinde bulunan 19 işletmenin 1997-2008 yılları arasındaki göreceli etkinliği (Öge ve Ayranc1, 2010: 13), İspanya'nın Katalan bölgesinde 1996-2001 yılları arasında faaliyet gösteren küçük ve orta ölçekli 66 firmanın teknik etkinliği (Kapelko, 2010: 133), Türkiye Cumhuriyet Merkez Bankası (TCMB) sektör bilançoları veri tabanında DB-17 ve DB-18 sektörlerinde faaliyet gösteren tekstil firmalarının 2006-2008 yılları arasındaki etkinliği (Kahveci, 2012: 29), Tayvan da 2007 y1lı krizi öncesi faaliyet gösteren 46 tekstil firmasının etkinliği (Lin ve Yahalom, 2012: 44), Eskişehir Organize Sanayi Bölgesinde 2008-2009 yıllarında faaliyet gösteren 5 tekstil işletmesinin ihracattaki etkinlikleri (Yenilmez ve Girginer, 2012: 12), dokuma esnasında ağızlık oluşumunun Hint dokuma sektörü üzerindeki etkinliği (Kumar vd., 2012: 28), Türkiye'de İSO ilk 500 firma sıralamasına giren ve 2008 ve 2010 yıllarında verilerine tam olarak ulaş1lan dokuma sektöründe faaliyet gösteren 19 firma ve giyim eşya sektöründe faaliyet gösteren 6 firmanın etkinlikleri (Yarar ve Çoban, 2012: 165), Tayvan da 
2010-2012 yılları arasında faaliyet gösteren en iyi 12 tekstil firmasının toplam etkinlikleri (Ho, 2013: 99), Çin'de faaliyet gösteren bir tekstil işletmesinin etkinliği (Kuo vd., 2013: 813), Türk hazır giyim perakende sektöründe faaliyet gösteren 30 firmanın 2010 y1lındaki etkinlikleri (Erdumlu ve Sarıçam, 2013: 237), Hindistan tekstil sektöründe etkinliği (Saeidi vd., 2013: 349), Pakistan tekstil sektöründe faaliyet gösteren 100 adet firmanın 2006-2011 yılları arasındaki etkinliği (Usman vd., 2014: 1683), İstanbul Sanayi Odası (İSO) 500 listesinde yer alan 30 tekstil ve hazır giyim firmasının 2012 yılı verilerine göre ihracat etkinlikleri (Öztürk ve Girginer, 2015: 10), Hindistan tekstil sektöründe 2011-2012 y1lları arasında faaliyet gösteren 10 tekstil firmasının teknik etkinliği (Verma vd., 2015: 34), TMS/TFRS öncesi (1998-2004) ve TMS/TFRS sonras1 (2005-2011) tekstil sektöründe faaliyet gösteren 13 işletmenin etkinliği (Kaya vd., 2015: 111) VZA yöntemi ile ölçülmüştür.

Literatürde yer alan çalışmalardan da anlaşılacağ1 üzere tekstil sektöründe etkinlik ölçümünde VZA yöntemi kullanılarak gerçekleştirilen çok sayıda çalışma yer almaktadır. Bu çalışma farklı bir işletmede yapılmasıyla ve karar verme birimi olarak da geçmiş yılları almasılyla literatürde yer alan diğer çalışmalardan farklılaşmaktadır. Çalışmaya konu olan işletmenin tekstil sektörünün bir alt grubu olan battaniye üretiminde faaliyet gösteriyor olması da bu araştırmanın bir diğer özgün tarafıdır.

\section{YÖNTEM}

VZA, parametrik olmayan bir yöntem olup etkinlik ölçümünde yaygın bir şekilde kullanılmaktadır. VZA ilk olarak Charnes, Cooper ve Rhodes tarafından geliştirilmiştir ve CCR modeli de böylelikle literatüre kazandırılmıştır. VZA'da kullanılan çeşitli modeller vardır. Ancak CCR modelleri ile Banker, Charnes ve Cooper tarafından geliştirilmiş olan BCC modelleri en temel modellerdendir.

$\mathrm{Bu}$ çalışmada etkinlik ölçümü yapılırken girdi odaklı CCR modelinden yararlanılmıştır. Girdi odaklı CCR modeli aşağıda gösterilen (1) nolu modeldir (Doğan, 2015: 194). Bu modelde, $j=1, \ldots, n$ olmak üzere $\lambda_{j}$, negatif olmayan skalerleri, $\theta_{0}$ ise etkinliği değerlendirilen KVBo'1 göstermektedir. Ölçeğe göre sabit getiri varsayımını dikkate alan bu modelde KVBo'ın etkin olması için 1 değerini alması gerekmektedir. Bu değer 1'den küçük olduğunda $\mathrm{KVB}_{0}$ etkin değildir. 
$\min \theta_{0}$

s.t.

$\sum_{j=1}^{n} \lambda_{j} x_{i j} \leq \theta_{0} x_{i 0}, \quad i=1, \ldots, m$

$\sum_{j=1}^{n} \lambda_{j} y_{r j} \geq y_{r 0}, r=1, \ldots, s$

$\lambda_{j} \geq 0, \quad j=1, \ldots, n$

$\mathrm{Bu}$ çalışmada tekstil sektöründe faaliyet gösteren bir imalat işletmesi ele alınmış ve bu işletmenin geçmiş son 16 yılındaki etkinlik ölçümü yapılmıştır. Çalışmada girdi olarak personel sayısı (PS), kullanılan hammadde miktarı (KHM) ve mevcut makine sayısı (MMS); çıktı olarak ise üretilen ürün sayısı (UUS) ve müşteri sayısı (MS) alınmıştır. Girdi ve çıktı verileri çalışmaya konu olan işletmenin üst düzey yöneticilerinden birisi ile yapilan yüz yüze görüşme sonucunda elde edilmiştir. Tablo 1'de yıl bazında işletmenin girdi / çıktı değişkenlerine ilişkin verileri özetlenmiştir.

Tablo.1. İşletmenin Son 16 Yıla İlişkin Girdi / Çıktı Değerleri

\begin{tabular}{|l|l|l|l|l|l|}
\hline \multirow{2}{*}{ YIL } & \multicolumn{3}{|c|}{ Girdiler } & \multicolumn{2}{c|}{ Ç1kt1lar } \\
\cline { 2 - 6 } & PS & KHM & MMS & UUS & MS \\
\hline 2015 & 36 & 715 & 35 & 195400 & 23 \\
\hline $\mathbf{2 0 1 4}$ & 32 & 620 & 30 & 159800 & 24 \\
\hline $\mathbf{2 0 1 3}$ & 30 & 585 & 30 & 145300 & 21 \\
\hline $\mathbf{2 0 1 2}$ & 28 & 490 & 28 & 142100 & 28 \\
\hline $\mathbf{2 0 1 1}$ & 25 & 424 & 24 & 133650 & 26 \\
\hline $\mathbf{2 0 1 0}$ & 24 & 412 & 24 & 128700 & 24 \\
\hline $\mathbf{2 0 0 9}$ & 23 & 391 & 22 & 118600 & 29 \\
\hline $\mathbf{2 0 0 8}$ & 23 & 386 & 22 & 115300 & 30 \\
\hline $\mathbf{2 0 0 7}$ & 22 & 375 & 22 & 112800 & 34 \\
\hline $\mathbf{2 0 0 6}$ & 21 & 362 & 20 & 96700 & 36 \\
\hline
\end{tabular}


Etkinlik Ölçümü: Tekstil Sektöründen Bir İşletme Örneği

\begin{tabular}{|l|l|l|l|l|l|}
\hline $\mathbf{2 0 0 5}$ & 20 & 354 & 20 & 83500 & 42 \\
\hline $\mathbf{2 0 0 4}$ & 20 & 347 & 20 & 78400 & 40 \\
\hline $\mathbf{2 0 0 3}$ & 18 & 322 & 17 & 68200 & 44 \\
\hline $\mathbf{2 0 0 2}$ & 17 & 316 & 17 & 61500 & 48 \\
\hline $\mathbf{2 0 0 1}$ & 15 & 304 & 15 & 56300 & 51 \\
\hline $\mathbf{2 0 0 0}$ & 15 & 298 & 15 & 48700 & 50 \\
\hline
\end{tabular}

\section{BULGULAR VE TARTIŞMA}

Analizlerde 3 girdi, 2 çıktı değişkeni kullanılmış ve girdi odaklı CCR modeli ile çözüm yapılmıştır (1 nolu model). Yapılan etkinlik ölçümü sonucunda elde edilen etkinlik skorları Tablo 2'de gösterilmiştir.

Tablo.2. Etkinlik Skorları

\begin{tabular}{|l|l|}
\hline Y11 & Etkinlik Skoru (\%) \\
\hline 2015 & 100,00 \\
\hline 2014 & 95,51 \\
\hline 2013 & 89,66 \\
\hline 2012 & 95,03 \\
\hline 2011 & 100,00 \\
\hline 2010 & 100,00 \\
\hline 2009 & 100,00 \\
\hline 2008 & 98,63 \\
\hline 2007 & 100,00 \\
\hline 2006 & 97,64 \\
\hline 2005 & 94,74 \\
\hline 2004 & 91,31 \\
\hline 2003 & 95,41 \\
\hline
\end{tabular}




\begin{tabular}{|l|l|}
\hline 2002 & 96,71 \\
\hline 2001 & 100,00 \\
\hline 2000 & 100,00 \\
\hline
\end{tabular}

Tablo 2'ye bakıldığında ilk sütunda karar verme birimleri olarak y1llar ve ikinci sütunda ise yüzde olarak etkinlik skorları yer almaktadır. İşletme, etkinlik skorunun 1 olduğu, diğer bir ifadeyle \% 100 olduğu y1llarda etkin, diğer yıllarda ise etkin değildir. Buna göre 2000, 2001, 2007, 2009, 2010, 2011 ve 2015 ylllarında olmak üzere işletme toplam yedi yılda etkin iken geriye kalan dokuz yılda ise etkin değildir.

\section{SONUÇLAR VE ÖNERILER}

Etkinlik kaynakların kullanılma oranına ilişkin bir kavramdır. Etkinlik ölçümü ile kaynakların nasıl kullanıldığı ile ilgili fikir yürütmek mümkündür. Bu çalışmada etkinlik ölçümü konusu ele alınmış ve bu konu Türkiye açısından önemli bir yere sahip olan tekstil sektöründe gerçekleştirilen bir uygulama ile incelenmiştir. Bu kapsamda sektörde faaliyet gösteren bir imalat işletmesindeki etkinlik ölçümüne odaklanılmıştır. Etkinlik ölçümünde VZA yönteminden yararlanılmış ve yöntemde yer alan modellerden CCR modeli kullanılmıştır.

Yapılan analiz sonucunda işletmenin, faaliyete başladığı tarihten itibaren geçen 16 yılın 7'sinde etkin olduğu ve geriye kalan 9 yılda ise etkin olmadığ sonucuna varılmıştır. Kaynakların optimum ya da optimuma yakın olarak kullanıldığ1 yıllarda işletme etkin, diğer yıllarda ise işletme etkin değildir. Söz konusu ölçüm sonuçları sektör ve özellikle işletmenin yöneticileri açısından fikir verebilecek cinsten bilgiler içermektedir. Ancak etkinlik skorları yorumlanırken VZA yönteminden elde edilen etkinlik ölçümünün göreceli bir etkinlik ölçümü olduğu unutulmamalıdır.

$\mathrm{Bu}$ çalışmada bir tekstil işletmesinin farklı y1llardaki etkinlik düzeyi ölçülmüştür. Burada her bir yıl bir karar verme birimi olarak alınmıştır. Çalışma tekstil sektörünün alt bölümlerinden birisi olan battaniye üretimi sektöründe gerçekleştirilmiş olmasıyla literatürdeki diğer çalışmalardan farklılaşmaktadır. Literatürde battaniye üretimi sektörü ile ilgili sınırlı sayıda araştırma vardır. Çalışma bu yönüyle de bu konuda araştırma yapacaklara ve sektördeki işletmecilere bir kolaylık sağlayabilecektir. Bu çalışmada 
VZA'daki girdi odaklı CCR modeli kullanılmıştır. Gelecekte bu çalışmadan farklı olarak çıktı odaklı CCR modeli ve bu modelin süper etkinlik modelinin kullanılması da bir başka çalışmaya konu olabilir. Gelecekte aynı sektördeki farklı işletmelerin karar verme birimi olarak alınacağı ve etkinlik bakımından kıyaslanacağı çalışmaların yapılması düşünülebilir.

\section{KAYNAKÇA}

ALÜFTEKIN, Nilay., Yüksel, Öznur., Taş, Ayşegül., vd. (2009), "Küresel krizden çıkıșta kümelenme modeli: Tekstil ve hazır giyim sektörü örneği”, Zonguldak Karaelmas Üniversitesi Sosyal Bilimler Dergisi, 5(10), 1-19.

BAKIRCI, Fehim. (2007), "Firma etkinliğini etkileyen faktörler: Türk tekstil sektöründe bir VZA ve TOBİT uygulaması", Ekev Akademi Dergisi, 11(30), 327-342.

BİLGì, Mualla. (2005), Battaniye sektör araşttrması, İstanbul Ticaret Odası Yayınları, İstanbul.

ÇETiN, Ali Cüneyt. (2006), "Türk tekstil sektörü ve Türk tekstil firmalarının etkinlik düzeylerinin belirlenmesi", Afyon Kocatepe Üniversitesi İ.I.B.F Dergisi, 8(2), 255-278.

DİNÇER, Erdal. (2008), "Veri zarflama analizinde malmquist endeksiyle toplam vektör verimliliği değişiminin incelenmesi ve İMKB üzerine bir uygulama", Marmara Üniversitesi İktisadi İdari Bilimler Fakültesi Dergisi, 25(2), 825-846.

DOĞAN, Nuri Özgür. (2015), "VZA süper etkinlik modelleri ile etkinlik ölçümü: Kapadokya'da faaliyet gösteren balon işletmeleri üzerine bir uygulama", Atatürk Üniversitesi İktisadi ve İdari Bilimler Dergisi, 29(1), 187-203.

ERDUMLU, Nazan., Sarıçam, Canan. (2013), "Türk hazır giyim parekendicilerinin etkinliklerinin ölçümü", Ege Akademik Bakış, 13(2), 237-244.

HO, Chia-Hui. (2013), "Applying data envelopment analysis to operating performance in textile industry", AUTEX Research Journal, 13(4), 99-103.

JOSHI, R.N., Singh, S.P. (2009), "Comperative performance of the Indian apparel firms", Journal of Managerial Economics, 7(3/4), 19-39.

KAHVECİ, Eyüp. (2012), "Kaynak Temelli Strateji ve ihracat performansi: Tekstil issletmeleri üzerinde veri zarflama analizi ile bir uygulama", Ankara Üniversitesi Sosyal Bilimler Fakültesi Dergisi, 67(2), 29-67.

KAPELKO, M. (2010), "Application of DEA model with bootstrap to evaluation of SMES effciency in the Spanish textile industry", International Workshop on Multiple Criteria Decision Making. 2010/2011, 133-148.

KAPELKO, Magdelena., Lansink, Alfons Oude. (2014), "Examining the relation between intangible assets and technical efficiency in the international textile and clothing industry", The Journal of The Textile Institute, 105(5), 491-501.

KAYA, Ahmet., Hatunoğlu, Zeynep., Özçalıc1, Mehmet. (2015), "Türkiye'deki tekstil firmalarının verimlilik değerlerinin TFRS öncesi ve sonrası dönemler İçin karşılaştırılması", Uluslararası Alanya İşletme Fakültesi Dergisi, 7(3), 111122.

KAYALI, Cevdet Alptekin. (2009), "2007 yll tekstil işletmelerinin finansal karlılık açısından etkinliklerinin değerlendirilmesi", Tekstil ve Konfeksiyon, 19(1), 38.

KUMAR, Ru., Grupta, A., Rathore, A.S. et al. (2012), "Relative Efficency of Weaving Industry in India Using Data Envelopment Analysis", International Journal of Advances in Management and Economics, 1(1), 28-36.

KUO, Chung-Feng Jeffry., Tzeng, Ren Er., Lan, Wei Lun. et al. (2013), "A study onb polyethylene terephtlate with titanium dioxide particles in melting spinning process parameters optimization", Textile Research Journal, 83(8), 813-826. 
LIN, Wen Chen., Yahalom, Shmuel. (2012), "Enchancing the efficiency of the benchmarking learning map model: The integrated FRA peerspective", Romanian Journal of Economic Forecasting, 15(3), 44-57.

ÖNGÜT, Ç Emrah. (2007), Türk tekstil ve hazır giyim sanayinin değişen dünya rekabet şartlarına uyumu, DPT yayınları, iktisadi sektörler ve koordinasyon genel müdürlüğü, Uzmanlık Tezi, Ankara, yayın No:2703.

ÖZTÜRK, Oğuzhan., Girginer, Nuray. (2015), "Türk tekstil ve hazır giyim firmalarının ihracat etkinliği: Veri zarflama analizi (VZA) ve analitik hiyerarşi süreci (AHS) kullanımiyla bir inceleme", Tekstil ve Konfeksiyon, 25(1),10-23.

ÖGE, Ercan., Ayranc1, Evren. (2010), "Ekonomik krizler ve Çin faktörü dikkate alındığında, İstanbul Menkul Kıymetler Borsası tekstil endeksinde bulunan işletmelerin ekinlikleri üzerine bir araştırma”, Anadolu Bil Meslek Yüksek Okulu Dergisi, 5(19), s.13-25.

SAEIDI, Reza G., Amin, Gholam.R., Raissi, Sadigh. et al. (2013), "An efficient DEA methot for ranking woven fabric detecs in textile manufacturing", International Journal of Advances Manufacturing Technology, 68(1), 349-354.

SARIÇAM, Canan., Erdumlu, Nazan. (2012), "Evaluating efficiency levels comparatively: data envelopment analysis application for turkish textile and apparel industry", Journal of Industrial Engineering and Management, 5(2), 518-531.

USMAN, Muhammed., Hassan, Ali., Mahmood, Farq. et al. (2014), "Performance of textile sector of Pakistan: application of data envelopment analysis approach", International Review of Mangement and Business Research, 3(3), 1683-1698.

VERMA, Smita., Kumavat, Ankit., Biswas, Anita. (2015), "Measurement of technical efficiency using data envelopment enalysis: A case of Indian textie industry", 3rd International Conference on Advances in Engineering Sciences \& Applied Mathematics (ICAESAM'2015) March 23-24, 2015 London (UK).

YAYAR, Rüştü., Çoban, Mustafa Necati. (2012), "İSO 500 firmalarının etkinliklerinin ölçülmesinde veri zarflama analizi yaklaşımı: Dokuma ve giyim eşya sanayi”, Niğde Üniversitesi İktisadi İdari Bilimler Fakültesi Dergisi, 5(2), 165-180.

YENILMEZ, Füsun., Girginer, Nuray. (2012), "Eskişehir organize sanayi bölgesindeki tekstil firmalarının ihracatlarındaki etkinliklerinin veri zarflama analizi (VZA) İle değerlendirilmesi”, Tekstil ve Konfeksiyon, 22(1),12-17.

YÜKÇÜ, Süleyman., Atağan, Gülşah. (2009), "Etkinlik, etkililik ve verimlilik kavramlarının yarattığı karışıklık", Atatürk Üniversitesi İktisadi ve İdari Bilimler Dergisi, 23(4), 1-13.

T.C. BİLìm VE SANAYİ BAKANLIĞI. (2014), "Tekstil, Hazır Giyim ve Deri Sanayi Sektör Raporları ", (erişim adresi: http://sanayipolitikalari.sanayi.gov.tr/Public/SectorStrategie/10), (erişim tarihi: 29.12.2016).

TÜIKK. (2016), "Yillı İstatistikleri ", (erişim adresi: http:// www.tuik.gov.tr/UstMenu.do?metod=temelist), (erişim tarihi: 29.12.2016). 